\title{
Organizational Knowledge: Ethics and the Importance of Trust
}

\author{
Gonçalo Jorge Morais da Costa*, Mary Prior, and Simon Rogerson \\ De Montfort University, The Gateway \\ Leicester, LE1 9BH, United Kingdom \\ goncaloj@netc.pt, mprior@dmu.ac.uk, srog@dmu.ac.uk
}

\begin{abstract}
The aim of this paper is to grasp the ethical dilemmas that arise into organizational knowledge and the importance of trust for diminishing these dilemmas. Therefore, it focuses three key issues: knowledge management (concept; and, schools of thought); knowledge flowing models versus ethics (mental models; the Socialization, Externalization, Combination, Internalization (SECI) model; and, Fiske's relational model); and finally, the importance of trust as a possible answer. Plus, this paper suggests that the previous models only focus knowledge as continuum process and the result of this process omits ethical and moral dilemmas (obligation to share, personal property, personal worth, autonomy, dignity, privacy, etc.). These ethical dilemmas clearly weaken a knowledge management project, and how trust is a reliable answer. The absence of empirical work should be considered a limitation of this paper; however, does not diminish the importance for this debate.
\end{abstract}

Keywords: Knowledge management; Organizational knowledge; Ethics; Organizational ethics; Trust.

\section{Introduction}

It is broadly recognized that society in which people live today has gradually been turned into a "global knowledge society" [1]. The knowledge society is a conception that has often appeared in the literature worldwide in recent years. The new era has also been referred by a variety of other authors: knowledge paradigm or to see the world from a knowledge perspective; knowledge economy; knowledge revolution or, knowledge capital era; knowledge era. Whatever name the "knowledge era" goes by, it is rewriting the rules of business and forcing a radical rethink of corporate values and business models of past eras, which means knowledge, is clearly a resource [2]. However, managers should realize that knowledge is bounded to people (human resources) and therefore, implicating a considerable amount of ethical and moral dilemmas through the "knowledge continuum process" (creation, retention, and sharing), which existent models of knowledge management seem to disregard.

So, knowledge is currently a key organizational resource for corporate success [3]. Plus, ethical dilemmas arise into a knowledge management project, and to recognize

\footnotetext{
${ }^{*}$ Corresponding author.

J.E. Quintela Varajão et al. (Eds.): CENTERIS 2010, Part II, CCIS 110, pp. 295-304, 2010.

(C) Springer-Verlag Berlin Heidelberg 2010
} 
these assumptions and the importance of trust is critical for managers, in order to reduce considerably the risk of losing organizational competitiveness. In conclusion, this paper discusses: the concept of knowledge management; the interaction of knowledge flow models with ethics; and, the importance of trust.

\section{Knowledge Management}

\subsection{The Concept}

During the literature review process it is possible to acknowledge several definitions regarding knowledge management, as for instance, the one of [4]: knowledge management is the acquisition and use of resources to create an environment in which information is accessible to individuals and in which individuals acquire, share and use that information to develop their own knowledge and are encouraged and enabled to apply their knowledge for the benefit of the organization. Nonetheless, [5] echoes that two myths exist concerning knowledge management technology's features: they deliver the right information to the right person at the right time; and, they can store human intelligence and experience (utopian perspective)!

Thus, a knowledge management project embraces two different concepts: the learning organization and organizational knowledge. Learning organizations are adaptive to their external environment, continually enhance their capability to change or adapt, develop collective, as well as, individual learning, and use the learning results to achieve better results [6]. Meanwhile, the essence of organizational knowledge entails two perspectives: "knowledge as a process" that focus the issues regarding creation, use and recreation, as well as, the dynamics of such process; and, "knowledge as a product", that spotlight the way knowledge is shared, used and stored. These analytical dimensions only recognize the process or the results, not embracing the ethical dilemmas that arise in organizational knowledge. So, this assumption imposes the following questions: can we encounter ethics concerning organizational knowledge? Do managers realize that these moral dilemmas exist?

\subsection{Schools of Thought}

Knowledge management is a reasonably recent research field, and therefore seems to engage a lack of conceptual stabilization, recognized by the insufficient empirical research and literature. Despite this conceptual youth, several schools of thought have arisen, originating a multiplicity of uses or applications in knowledge management. Form them it is possible to distinguish three perceptions considering dissimilar geographical and historical contexts, as well as traditions or cultures that propitiate a theoretical orientation. A further analysis, allow us to catalogue these orientations as "more Japanese", "more European" and, as "more American."

The first school argues that organizations are conceived as creative "entities of knowledge", and for that, pleading the idea that knowledge is a process as [7], [8] demonstrate. The second approach assumes as presupposition the attempt to measure knowledge resources, namely through some European authors [9], seeking to audit intangible resources, accountancy and publishing, through intellectual capital indicators and appropriate systems that allow its measurement and popularization. Finally, 
the third perspective engages technology's potential as a supportive tool to organizational processes, relating them with knowledge generation and management. Information and communication technology's are considered relevant to knowledge management, because they make possible optimization regarding extracting, structuring, codifying, storage, recovering and applying individual and organizational knowledge (see for example of [10]).

\section{Knowledge Flow Models vs. Ethics}

\subsection{Mental Models vs. Ethics}

Organizational context can be characterized as a melting pot of people. People that present innate skills in different levels, which means in each step in the reasoning process of the problem solver we will have different "analytical speed" [11], which means that workers less faster in their mental construction (or internal representation) of the problem situation could be dependent of other workers. Another important question to be raised is: in a sharing environment can we morally oblige people to work faster than their innate skills [12]?

Another important issue to focus is the implicit truth of a propositional logic. In spite of, [13] pleads the principle of truth in a human reasoner (particularly one that is ignorant of formal logic), is more likely to construct a model of what is true in presented information rather than of what is false: so the argument can be criticized... The main law of biology is the survival of the strongest and for that, competition is intrinsically bounded to that subject. In that sense, can we automatically deduce that people are constructing mental models based on truth when they have to share it [14]? As a form of defence, people can try to modify such principle, or during the transmission process can engage a different perspective on their mental construction.

\subsection{SECI Model vs. Ethics}

Researchers have created several frameworks and classifications concerning the existent types of knowledge transfer. For instance, [15] identifies five knowledge transfer situations usually seen in practice: serial transfer, near transfer, far transfer, strategic transfer, and expert transfer. Adopting a different perspective based on the actors involved in the process of knowledge transfer, [16] discerns four types, namely shared work producers, shared-work practitioners, expertise seeking novices, and secondary knowledge miners.

These frameworks, however, focus primarily on concepts such as the purpose of knowledge transfer, the actor involved (knowledge consumer, knowledge intermediary, or knowledge provider), the kind of knowledge needed, and challenges in finding and selecting knowledge. Research and commentary around the issue of ethics in knowledge transfer usually does not distinguish between knowledge transfer and knowledge sharing; however, the former has an instrumental connotation while the latter has a social connotation. This research has regarded the creation of ethical environments that promote sharing [17]; utopian organizational cultures and communities of knowledge sharing [18]; the paradox of the trade-off between holding personal tacit knowledge for individual productivity versus sharing that knowledge for 
organizational productivity [19]; and the use of ethics and self-interest as counter determinants of knowledge sharing [20]. Thus, the ethics of knowledge transfers and conversions become extremely important due to the individual loses sole rights to knowledge. Is this a transfer of property or personal worth [21]?

As an individual's private attribute, organizational programs that aim to forcibly develop knowledge-sharing cultures could violate individual privacy rights. These violations could become central in the ongoing debate regarding human rights protection, as a responsibility of multinational companies as well as governments. Do organizations "own" their employees knowledge, or is this knowledge an "attribute" of an autonomous individual and subject to protection under human rights to privacy or security-of-person? Is the development of knowledge-sharing organizational structures the rightful exercise of organizational intellectual property rights, or is it an invasion of worker privacy? Must there be an explicit employment contract that defines these intellectual property rights in a fairly manner [21].

Knowledge exists in different forms, and different forms may involve different conflicts. The conflicts sometimes pit organizational rights to knowledge against individual rights to knowledge. Such rights arise from accepted human rights frameworks that include property rights and privacy rights [22], and therefore this conflict is framed by cultural values that are shaped by national boundaries and organizational norms.

There is a debate whether knowledge can exist beyond the individual. This question seems to rests on how we define knowledge. Some definitions of knowledge emerge from the field of expert systems, encompassing structures beyond just information to include the rules for processing information. Other definitions arise from the viewpoint of knowledge as an organizational property, similar to a knowledge base, that encompasses routines and processes that contextualize information and enable action. Still others characterize knowledge as an innately human attribute, something that resides in the living mind of a person, because the mind must identify, interpret and internalize knowledge.

From a different perspective, organizational knowledge is also a knowledge asset or the "firm-specific resources that are indispensable to create values for the firm" [7]. Given their unique characteristics, knowledge assets cannot be immediately sold or bought. This is especially valid if knowledge assets are not in an articulated form but rather in the employees' minds or as know-how [7]. Consequently, buying and selling organizational knowledge involves transferring groups of individuals with established patterns of working together. These transactions can be achieved through knowledge alliances, joint ventures, mergers and acquisitions. The potential for hostile mergers and acquisitions opens avenues for the seizure of rights to individual knowledge by organizations whose ethical posture might contravene the moral beliefs of some of these individuals.

Moreover, organizational knowledge has a limited commercial value if it is not embedded in a particular setting. For instance, managerial experience and knowledge about customers, suppliers and competitors is "trapped inside the minds of keyemployees" [7] and therefore, this knowledge may be useless. This observation offers additional support to our argument that an organization has the right of property over the employees' organizational knowledge. Hence, organizations depend on employees' behaviour to create and to transfer knowledge [23]. 
Personal knowledge may be excluded from manageable knowledge. For example, Klynveld Peat Marwick Goerdeler (KPMG) defines intellectual property as "not just patents, trademarks, copyrights, database rights and other pure intellectual property, but other forms of articulated knowledge, such as business processes, methodologies and know how" [24]. This means that some organizations will not consider personal knowledge as intellectual property. The transfer of personal knowledge is not well understood, and is often regarded by economists and social scientists using a "costfree" assumption. Instead, the transfer of tacit knowledge is known to be difficult without the transfer of people. In some ways, personal knowledge is regarded as more easily managed, since it can be "more readily bought and sold" by hiring and firing individuals [7], which the authors do not agree.

Thus, the transfer of personal knowledge engages ethical decisions regarding personal worth. Not surprisingly, a circumspect employee might withhold personal knowledge and avoid sharing knowledge. An employee might hold back his personal knowledge in the interest of maintaining job security [19]. This holding also arises self-interest issues, namely when organizational culture views knowledge sharing as a setting of reciprocity, or strong competition for performance among workers within the organization [20].

\subsection{Fiske's Relational Model vs. Ethics}

Within communal sharing relationships, knowledge is perceived as a common resource, rather than an individual property. Knowledge is not personally marked, since it belongs to the whole group. Knowledge is freely shared among people belonging to the same group or dyad, following the idea "what's mine is yours", and however some common substance is required. It is important to realize that this common substance between people can be based on different objects or different grounds for cohesion, which means a dilemma: do people of different groups' value in the same way the sense of membership [25]? Although communal sharing is frequently not the dominant structure for sharing knowledge organization-wide, there might exist some subsets within the organizational context where knowledge is being shared. Furthermore, people might share knowledge with others, since they feel connected with them based on shared ideological objectives or based on solidarity, which implies another dilemma: if "what's mine is yours" how it is possible that the model advocates that communal sharing is not the dominant structure [26]? Supposedly, if knowledge is a common resource should be longitudinal to the organization.

In authority ranking knowledge is perceived as a mean to display rank differences, whether rank is based on formal power, expertise or age. Higher a person's rank better access to knowledge [27]. A person with a higher rank, that shares knowledge with someone lower in rank demonstrates his nobility and largesse and expects to get authority or status in return. A subordinate shares knowledge because either he has to or, because he wants to gain favour with his superior. In both cases the subordinate can expect a kind of "pastoral care" in return. In this respect knowledge sharing is motivated by power differences [28]. People are less or not willing to share knowledge when it can change their balance of power negatively. "Negative" knowledge is frequently withheld by window dressing behaviour and a knowledge overload may originate from largesse and sweet-talk, which generates the following question: you 
people evaluate negative knowledge (negative knowledge can be seen as gossip) [29]? There is a standard evaluation process to power balancing regarding knowledge?

Within equality matching relationships knowledge is perceived as a mean of levelling out knowledge sharing efforts. The principle behind knowledge sharing is based on the exchange of knowledge for similar knowledge. Knowledge is being shared because someone else has shared something similar before or, because one expects something similar in return. It is the desire for equality that motivates knowledge sharing. But in ethical terms how could a person identify equality [28]? Quantifying knowledge, for example, you shared two pages of knowledge? This does not seem reasonable. Or qualifying that shared knowledge, for instance, you share highly quality knowledge; but does that knowledge represent the same quality? A person could already know what is being shared. Plus, can we morally obliged a person to share something in return by sharing knowledge oneself [21]? People are less or not willing to share knowledge when nothing similar can be shared in return within a reasonable time span [27].

Into market pricing relationships knowledge is perceived as a commodity which has a value and can be traded. Knowledge is being shared because one receives a compensation for it (not being similar knowledge or status). People are motivated to share knowledge by achievement. When the perceived compensation is not high enough, people are less or not willing to share knowledge, so which means a dilemma: if knowledge is traded to whom belongs the intellectual property? And in ethical terms, what happens when people, organizations, or even countries cannot obtain such knowledge due to their budget restrictions? [30] So a "knowledge divide" is created.

\section{The Importance of Trust}

Trust involves risk taking; that is, both parties know that the actions of one party can materially influence the other, but both share ideas, concerns or issues truthfully notwithstanding. The sociological literature conceptualizes trust as either the property of individuals, social relationships, or the social system with disproportionate attention to behaviour based on actions at an individual level [31]. When seen as a characteristic or property of individuals, trust is a personality variable, thereby placing accent on individual characteristics like feelings, emotions, and values. A second perspective observes trust as a collective attribute that can be drawn upon to achieve organizational aims. It may therefore be applied to the institutional basics of society. The third treats trust as a valued public good facilitated and sustained by a social system.

These three dissimilar levels of trust are interrelated. On the individual level, you trust an individual to do something based on what you know of his disposition, his ability, his reputation and so forth not merely because he says he will do it. On the collective level, if you don't trust an agency or organization with which the individual is affiliated, you will not trust him to fulfil an agreement [32]. In addition, individuals consider the background, culture, and social system of another when seeking to determine whether to trust him. It is the interconnectedness that advocates how building trust on the micro-level contributes to the determinant of a more abstract form of trust on the macro-level [33]. 
Moreover, a considerable number of academics contend that trust is rather difficult to produce intentionally. For example, Coleman suggests that as a rational account of human behaviour, trust can only be produced in informal, small, closed and homogeneous communities which are able to enforce normative sanctions [34]. It is unclear how; precisely, to create trust within communities, especially in diverse or heterogeneous societies, or as [35] states insecurity and conformity may produce such results. Still, many researchers continue to search for conditions that may help to facilitate trust and thereby allow efforts to create it deliberately.

Trust is a social mechanism that is embodied in structures of social relations. Social structure is important not only for the formation of social capital, but also for the generation of trust itself. It allows a more rapid proliferation of obligations and expectations, imposing sanctions on defection from an obligation, and helps to generate reputation [34]. In addition to social relations, shared norms are a source of trust, as pointed out by [36] defines trust as "the expectation that arises within a community of regular, honest, and cooperative behaviour, based on commonly shared norms, on the part of other members of the community."

As explained previously knowledge can be categorized along a continuum running from the explicit to the tacit; and, the "natural" process of knowledge management in an organizational context is the dynamic transformation process, and governing the worker's need to create, capture and share knowledge. For that, managers should create a favourable atmosphere, where knowledge that is not protected through legislation is not an inhibition factor for workers. In that context another problem arises, to whom belong the intellectual property rights: to the worker that transformed tacit knowledge into explicit knowledge, to a team of workers, or to the organization that supplied the atmosphere and necessary means? A clear position by the managers will allow a clear answer.

So far, we have considered the need of trust in knowledge sharing and knowledge protection, but what can be considered as correct and wrong in knowledge change? The challenge that managers face is complex [37], because it not only depends on organizational core values, but also the ethical code of each worker. In fact, workers behaviours or attitudes (values) dynamics can be contradictory to organizational values [38] or not, assuming that organizational values socialize them in some key issues [39]. Beside the previous analysis managers own discourse also face ethics as [40] states. A stance ethical discourse entails stringent requirements for those in the organization. The primary responsibilities inherent in the organizational ontology by the discourse ethics, then, stand or fall on two assumptions:

- $\quad$ normative claims to be valid have cognitive meaning and can be treated like claims to truth;

- the justification of norms and commands requires that a real discourse be carried out and thus cannot occur in a strictly monological form.

The first assumption is vital, but it places a particular responsibility on every speaker. What is said must be believed by the speaker and should have a rational basis. More specifically, a claim may well warrant assessment, but the assessment should be made on rational epistemological grounds, rather than on preferences or biases. It should be noted that rationality introduced is not the reductionist plead by some economists. The reduction may frequently take the form of quantification, which is valid and necessary 
most of the time, but obscure at other circumstances. Most organizations have some form of hierarchical structure, which is necessary to ensure that decisions are made and directions are chosen. And, the communicative action is not easy or simple. It requires an ethical stance that recognizes that every individual entails a commitment to truth, leading to trust.

\section{Conclusion}

It is clear that any model configures a reality representation, meaning that errors in its conception are admissible. Beside, knowledge management is a recent research field leading to plausible critics to the existent models. So, this paper aims not to suggest that these knowledge flow models are invalid, but to reinforce the idea that is essential to evaluate the existent ethical and moral issues that occur during the process of generation, creation and use of knowledge within an organization. However, mental models entail mental fluxes, therefore the praxis for understand personal knowledge meaning that is not comparable with an organizational "stream"; the other models at some extent can be compared because both debate organizational flows, however aiming for dissimilar contexts. The first debates organizational in a traditional sense (companies), and the second as collective/societal knowledge.

Although, can trust be the "key" for diminish these ethical dilemmas? Having in consideration all the previous sections, it seems that indeed trust plays as a vital role; nonetheless, a definitive answer is extremely difficult to obtain because contexts are not easily reproduced; so, each organization represents a case study and a possible different answer, leading to a necessary analysis off organizational values, managers values and workers values within that specific organization.

Acknowledgments. The first co-author of this paper would like to distinguish the remarkable endeavour of Ms. Mary Prior and Professor Simon Rogerson regarding their support, as well as to Nuno Sotero Alves da Silva for his insightful comments and critics to the previous versions of this contribution. Finally, also to thanks ISLA Leiria for its financial assistance with reference to CENTERIS 2010.

\section{References}

1. Savage, C.: http: / / www . kee-inc. com/dawn

2. Nicolau, I.: A Gestão do Conhecimento como Instrumento para a Gestão Competitiva. Revista Economia Global \& Gestão 2(10), 21-44 (2005)

3. Martion-Rios, C., Erhardt, N.L.: Organisational Knowledge Transfer Through Human Resource Management: International Diffusion of Managerial Performance Management. European Journal of International Management 2(2), 170-191 (2008)

4. Brelade, S., Harman, C.: A Practical Guide to Knowledge Management. Thorogood, S.1. (2003)

5. Malhotra, Y.: Why Knowledge Management Systems Fail? Enablers and Constraints of Knowledge Management in Human Enterprises. In: Koening, M., Srikantaiah, T. (eds.) Handbook on Knowledge, pp. 87-112. Springer, Heidelberg (2004) 
6. Bennet, D., Bennet, A.: The Rise of the Knowledge Organization. In: Holsapple, C. (ed.) Handbook on Knowledge Management, pp. 5-20. Springer, New York (2004)

7. Nonaka, I., Teece, D.J.: Managing Industrial Knowledge: Creation, Transfer and Utilization. Sage Publications, London (2001)

8. Nonaka, I., Toyama, R., Byosiere, P.: A Theory of Organizational Knowledge Creation: Understanding the Dynamic Process of Creating Knowledge. In: Dierks, C., Antal, A., Child, J., Nonaka, I. (eds.) The Organizational Learning and Knowledge, pp. 491-517. Oxford University Press, New York (2003)

9. IAS 38: International Accounting Standards 38 intangible Assets. International Financial Reporting Standards, London (2003)

10. Lampropoulos, L., Michalakos, S., Anagnostopoulos, A., Pouloudi, N.: Enabling the Exploitation of Tacit Knowledge: Open Issues and Opportunities. In: ETHICOMP 2005, paper 39. Linkoping University, Linkoping (2005)

11. Nesse, R.M., Lloyd, A.T.: The Evolution of Psychodynamic Mechanisms. In: Barkow, J., Cosmides, L., Tooby, J. (eds.) The Adapted Mind: Evolutionary Psychology and the Generation of Culture, pp. 601-626. Oxford University Press, New York (1992)

12. Goldman, A.I.: Ethics and Cognitive Science. Ethics 103, 337-360 (1993)

13. Fiske, A.P., Haslam, N., Fiske, S.T.: Confusing One Person with Another: What Errors Reveal About the Elementary Forms of Social Relations. Journal of Personality and Social Psychology 60(5), 656-674 (1991)

14. Lohman, D.F.: Reasoning Abilities. In: Sternberg, R., Davidson, J., Pretz, J. (eds.) Cognition and Intelligence: Identifying Mechanisms of the Mind, pp. 225-250. Cambridge University Press, New York (2005)

15. Dixon, N.M.: Common Knowledge: How Companies Thrive by Sharing What They Know. Harvard Business School Press, Boston (2000)

16. Markus, M.L.: Toward a Theory of Knowledge Reuse: Types of Knowledge Reuse Situations and Factors in Reuse Success. Journal of Management Information Systems 18(1), 57-93 (2001)

17. McDaniel, C.: Theoretical Issues in Organizational Ethics. In: McDaniel, C. (ed.) Organizational Ethics: Research and Ethical Challenges, pp. 17-38. Cornwall, Asghate (2004)

18. Wilson, T.D.: The Nonsense of Knowledge Management. Information Research, 8 (2002), http: / / informationr.net/ir/8-1/paper144.html

19. Costa, G.J.M., Prior, M., Rogerson, S.: Individual Ethics and Knowledge Management: Arising Conflicts. In: ETHICOMP 2010, pp. 117-129. University of Pavia, Mantua (2008)

20. Wang, C.-C.: The Influence of Ethical and Self-Interest Concerns on Knowledge Sharing Intentions Among Managers: An Empirical Study. International Journal of Management 21(3), 370-381 (2004)

21. Du Plessis, J.C., Britz, J.J.: Slave or Sibling: A Moral Reframing the Corporate Knowledge Sharing Community. Open University, Johannesburg (2007)

22. Dulipovici, A., Baskerville, R.: Conflicts Between Privacy and Property: The Discourse in Personal and Organizational Knowledge. The Journal of Strategic Information Systems 16(2), 187-213 (2007)

23. Bock, G.W., Zmud, R.W., Kim, Y.-G., Lee, J.N.: Behavioural Intention Formation in Knowledge Sharing: Examining the Roles of Extrinsic Motivators, Socialpsychological Forces, and Organizational Climate. MIS Quarterly 29(1), 87-111 (2005)

24. KPMG: Intellectual Gold- KPMG's European Intellectual Property Survey Reveals the Value Hidden in Europe's Leading Companies. KLegal, London (2002) 
25. Verweij, M.: Towards a Theory of Constrained Relativism: Comparing and Combining the Work of Pierre Bordieu, Mary Douglas and Michael Thompson, and Alan Fiske. Sociological Research Online, 12 (2007), http://ideas.repec.org/s/sro/srosro.html

26. Gannon, M.J.: Cultural Metaphors: Their Use in Management Practice and as a Method for Understanding Cultures. In: Lonner, W.J., Dinel, D.L., Hayes, S.A., Sattler, D.N. (eds.) Online Readings in Psychology and Culture, Center for Cross-Cultural Research, Western Washington University, Bellingham (2002)

27. Bolender, J.: The Genealogy of the Moral Modules. Minds and Machines 13(2), 233-255 (2003)

28. Bolender, J.: Two Accounts of Moral Diversity: The Cognitive Science of Pluralism and Absolutism. Yediteped́e Felsefe 1(3), 52-110 (2004)

29. Michelson, G., Mouly, S.V.: You Didn't Hear it From Us But... Towards an Understanding of Rumour and Gossip in Organizations. Australian Journal of Management 27, 57-65 (2002)

30. Costa, G.J.M.: The Handbook of Ethical Issues and Social Dilemmas in Knowledge Management: Organizational Innovation. IGI Global, Hershey (in Press)

31. Misztal, B.A.: Trust in Modern Societies: The Search for the Bases of Social Order. Polity Press, Cambridge (1996)

32. Schoorman, F.D., Mayer, R.C., Davis, J.H.: An Integrative Model of Organizational Trust: Past, Present, and Future. Academy of Management Review 32(2), 344-354 (2007)

33. Uslaner, U.M.: The Foundations of Trust: Micro and Macro. Cambridge Journal of Economics 32(2), 289-294 (2008)

34. Coleman, J.S.: Foundations of Social Theory. Harvard University Press, Cambridge (1990)

35. Yair, G.: Insecurity, Conformity and Community: James Colemanś Latent Theoretical Model of Action. European Journal of Social Theory 11(1), 51-70 (2008)

36. Fukuyama, F.: Trust: Social Virtues and the Creation of Prosperity. Free Press, New York (1995)

37. Sackett, P.R., DeVore, C.J.: Counterproductive Behaviours at Work. In: Anderson, N., Ones, D.S., Sinangil, K.S., Viswesvaran, C. (eds.) Handbook of Industrial, Work and Organizational Psychology, pp. 145-164. Sage, London (2002)

38. Costa, G.J.M., Prior, M., Rogerson, S.: Trustworthy and Ethical Environment in Knowledge Management: A Dilemma to Solve! In: Network Ethics 2009 (2009); just presentation, Lisbon

39. Taormina, R.J.: Interrelating Leadership Behaviours, Organizational Socialization, and Organizational Culture. Leadership \& Organizational Culture 29(1), 85-102 (2008)

40. Rhen, A.: Good Times, Bad Times- The Moral Discourse of Time and Management. Revista Comportamento Organizacional \& Gestão 8(1), 49-59 (2002) 